\title{
USING FUZZY AHP AND FUZZY TOPSIS APPROACHES FOR ASSESSING SAFETY CONDITIONS AT WORKSITES IN CONSTRUCTION INDUSTRY
}

\author{
A. BASAHEL \& O. TAYLAN \\ Department of Industrial Engineering, Faculty of Engineering, \\ King Abdulaziz University, Jeddah, Saudi Arabia.
}

\begin{abstract}
Providing safe workplace conditions is one of the main purposes of a safety management system (SMS) in effective construction companies. Ensuring safe workplace conditions at construction sites depends on different factors, including safety rules, management commitment, safety training, and safe behaviour. The current research aims to establish a method for identifying and evaluating the factors that impact workplace safety conditions at construction sites in Saudi Arabia. The fuzzy analytical hierarchy process (AHP) technique was used to determine and measure the qualitative factor weights affecting workplace safety to assist in the evaluation of multiple concurrent criteria. Hence, the fuzzy AHP technique was used to determine criterion weight. Alternatively, a fuzzy technique for Order Performance by Similarity to Ideal Solution (TOPSIS) model was used to evaluate the performance of companies and rank them according to their safety performance. Based on the results and findings of the presented approaches, four companies were ranked for their overall safety performance. The findings are encouraging and can be used in the construction industry to benchmark the performance of construction companies for their application of safety rules and regulations. The approach also determines the leading companies in terms of best practices and provides information for government inspectors to investigate the priorities identified for inspection.
\end{abstract}

Keywords: construction worksites, fuzzy AHP, fuzzy TOPSIS, safety behaviour, safety management, safety procedures, safety training.

\section{INTRODUCTION}

A safety management system (SMS) aims to decrease the number of accidents, injuries, and health problems among workers at a workplace. The effectiveness of the system depends on different factors, such as management commitment, effective use of resources, and worker participation, and communications. The scope and complexity of SMSs vary according to the size and type of workplace. Vinodkumar and Bhasi [1] stated that one of the most important functions of an SMS is to provide safe workplace conditions that significantly impact the health and productivity of workers and support the construction company's financial status. For example, poor worksite safety increases the likelihood of serious accidents in construction as compared to other sectors, such as manufacturing [2]. Serious injuries and accidents, particularly fatal accidents, are more likely to occur on construction worksites than on sites in other industrial sectors [2,3]. One of the most important responsibilities of an SMS is to perform risk assessment and hazard analyses to protect people and provide a safe workplace; these processes depend on several factors, such as management commitment, safety policies, safety rules and procedures, safety training, and safe behaviour [1, 4]. Teo and Ling [5] found that a lack of safety auditing leads to poor safety performance and a lack of improvement. The factors that affect workplace safety in the construction industry are often not physical, as they depend on different objective factors (e.g., the number of injuries and accidents) and subjective factors (e.g., safe behaviour, responsibility, and time pressure) [6]. Therefore, safety on construction sites is a complex issue. Workplace accidents can occur due to poor 
safety attitudes, lack of knowledge, poor training programmes, and insufficient supervision - even when the company provides an adequate safety policy and clear safety rules and procedures. For example, safe behaviour is one of the most significant subjective factors that may lead to accidents at construction worksites and can thus affect a company's SMS performance $[1,7,8]$. The factors that affect workplace safety at construction sites are not uniform; they can involve management commitment and safe behaviour, training, rules, and procedures [1]. According to Ismail et al. [9], the commitment of management to safety and safety regulations are two other major factors that influence organizational safety performance. Therefore, the factors that significantly affect worksites' safety-management performance must be identified to increase safety and avoid accidents.

However, these factors can affect workplace safety simultaneously. For example, safety culture and safe behaviour are two important organizational factors that significantly affect safety at construction sites [10]. According to Zou and Sunindijo [11], safety culture comprises beliefs and attitudes about safety and behaviour that are shared between workers within an organization. Ismail et al. [9] claimed that there is correlation between safe behaviour, safety rules, and legalization and management commitment. Consequently, measuring these factors would be more reasonable and reliable if conducted via multidimensional systematic techniques. In addition, the majority of previous research studies have focused on assessing the impact of ergonomic hazards at construction sites. Ergonomic factors in workplaces are typically physical structures; however, as noted above, workplace safety depends on subjective and multidimensional factors, each of which has a different level of importance [4].

Various factors have been considered in evaluating the management systems of construction organizations, including safety policy, safety culture, individual behaviour, job stress, safety training, management commitment, individual responsibility, safety communications, safety rules, and guidelines [10]. In addition, the methods used will vary due to the number of accidents and the cost complaints, interviews, and surveys. Several studies have evaluated workplace safety using a fuzzy analytical hierarchy process (AHP) model, especially in the construction industry [5]. However, Dagdeviren and Yuksel [12] did not consider important factors in construction site safety, such as safety rules and procedures, safety training, and management commitment. In contrast, other authors used only a weighted AHP method to evaluate the factors that influence safety management [5]. The fuzzy AHP technique is a useful method in this case, as it allows researchers to evaluate multiple worksite safety factors concurrently and helps them to evaluate the subjective factors that impact workplace safety using fuzzy numbers when these factors cannot be measured with crisp numbers [12]. Therefore, the present study used a fuzzy AHP method to evaluate the various factors that influence workplace safety at the construction sites of major Saudi Arabian construction companies.

The current research used systematic techniques to assess five main factors that affect safety performance at construction worksites, namely, site management level, safety training, safe behaviour, safety procedures and rules, and worker team level. Therefore, the present study used a fuzzy AHP method to determine the most important factors for workplace safety performance. One of the main advantages of the fuzzy AHP method is that it is able to simultaneously evaluate the effects of different factors in realistic situations. The fuzzy Technique for Order Performance by Similarity to Ideal Solution (TOPSIS) method is used to objectively assess construction companies in terms of their safety performance.

The fuzzy AHP method helps decision makers determine the factors that are most likely to be the cause of unsafe work conditions. This method assigns weights to determine the factors' importance. Determining the weights of various factors is one management function that a 
company should consider to improve the safety conditions at worksites. Unfortunately, the fuzzy AHP method is rarely used to evaluate the factors that affect workplace safety in construction companies [10]. Taylan et al. [13] studied different methods, such as AHP, fuzzy AHP, TOPSIS, and fuzzy TOPSIS, and found that combining these methods, rather than using one method separately, has both advantages and disadvantages. The combination of the fuzzy AHP and TOPSIS methods is more beneficial than using either method individually. In the hybrid methodologies, qualitative and quantitative data related to SMS criteria must be collected and used to assess the companies' overall performance. The fuzzy TOPSIS method is suitable for solving group decision-making problems in a fuzzy environment. It is an attractive method for selection problems in which the criteria are equally important and the information related to the input criteria is not precisely known. The alternatives are evaluated based on different criteria, and the evaluation process involves mainly quantitative data. However, some difficulties exist when quantitative data are not available; hence, a ranked value judgement on a fuzzy conversion scale is used in this case. If the value of criteria can be determined using fuzzy linguistic terms, then the outcomes are converted into corresponding fuzzy numbers and then defuzzified as crisp assessment scores. Aguaron et al. [14] determined that Saaty's [15] AHP model assured the consistent analysis of judgements and was more robust than the other decision-making methods.

According to Ismail et al. [9], the factors that influence construction worksites' safety-management performance are not identical in all countries or organizations. For example, safety rules and procedures in SMSs depend on a country's regulations and laws as well as on the nature of the organization's activities. Consequently, it is helpful to establish a fuzzy AHP model to assess the factors that affect construction worksites in such a situation. This model can also support safety management in identifying the factors that have the largest impact on safety system performance. Dagdeviren and Yuksel [12] stated that many previous studies have focussed on objective measures, such as number of injuries, number of lost working days, and risk assessments, when evaluating an SMS performance, in particular at construction industry sectors. Using systematic approaches and subjective methods, such as AHP fuzzy technique, to assess impacts on different factors that can affect safety-management effectiveness at construction companies is rare in terms of safety issues. In general, the evaluation of safety-management performance via subjective techniques, such as the fuzzy AHP method, have received little attention in all studies that have been conducted amongst the construction industries in Saudi Arabia. Therefore, the contribution of the current study is that it establishes a model that applies fuzzy AHP and TOPSIS methods, which assess factors that could influence SMS at large Saudi companies' construction sites. Performance assessment of companies is a highly complex multidisciplinary task, the decision criteria are non-linear, and several quantitative and qualitative attributes have to be taken into consideration. It is very hard to find all criteria and sub-criteria together for decision making in the assessment performance assessment. The criteria and sub-criteria set is able to be used for the development of a decision support system and even for the expert system to assess the safety performance of companies. Moreover, four decision makers are involved in the decisionmaking process. Hence, the criteria determination, and hybridization of Fuzzy AHP and fuzzy TOPSIS is the base of the fuzzy model developed.

The literature on SMSs, fuzzy AHP, and TOPSIS approaches are presented in the introduction. Section 2 is devoted to the fuzzy decision methodologies for SMS. In this section, the factors at construction worksites as well as the uncertainties were given, and the safety performance elements by fuzzy sets were presented. This section also covers the detail steps of 
the fuzzy AHP method. Section 3 includes fuzzy TOPSIS methodology for assessing the SMS. Section 3.1 presents the results and findings of the applied methodologies step by step and the key elements to order the companies according to their safety performance. Finally, Section 4 draws the conclusions and makes final remarks. The paper ends with a list of references.

\section{THE FUZZY DECISION-MAKING METHODOLOGY FOR A SAFETY MANAGEMENT SYSTEM}

The fuzzy AHP and fuzzy TOPSIS approaches are used in this study to evaluate the factors that contribute significantly to SMS performance at construction worksites. Furthermore, the construction companies considered were ranked according to their SMS performance, as described in the following subsections.

\subsection{Identification of factors' impacts on SMS at construction worksites and uncertainty}

As illustrated in Fig. 1, the five main factors in the current model that contribute to the assessment of construction worksites' SMS were carefully identified and structured from the literature review as well as from several experts from the construction-safety field. Four male expert safety managers and safety advisors from four different large Saudi construction companies participated. The statistical characteristics (i.e. mean $\pm \mathrm{SD}$ ) of the participants are as follows: age: $43.3 \pm 2.4$; duration of employment in safety positions: $16.7 \pm 4.1$ years. Three participants held master's degrees, and the fourth had a BSc degree. However, based on previous research studies and expert participants (i.e. specialists in safety management and risk assessment in Saudi construction companies), the main factors that can significantly impact SMS performance are classified into five factors: safety-management level, safety training, safety behaviour, safety procedures and rules, and worker team level. This is consistent with previous research studies that mentioned safety training programmes, safety behaviour, safety communication and feedback, safety rules, management commitment, and individual safety performance $[1,4]$. The safety-management level includes safety priority, management commitment, safety facilities' conditions, safety meetings, and safety reports. A high level of management commitment in safety issues means that the company strives for good safety conditions, appropriate safety welfare, and highly prioritizes safety. These factors have a positive, significant impact on how employees and the lower management feel about safety at the worksites. Safety training involves safety training programmes, training priority, and participation. Training programmes contribute significantly to reducing accidents and the number of injuries at worksites. Suitable training programmes help workers identify common types of hazards and how they can deal with them. In addition, increasing workers' participation in effective training programmes leads to increased levels of knowledge and skill amongst workers regarding types of hazards at worksites, which decreases the number of injuries and accidents and impacts the overall SMS performance. Safety behaviour is impacted significantly by management commitment, which comprises three sub-factors: performance tendency, safety-rules compliance, and safety awareness. Safety behaviour is an important factor that can impact SMS performance negatively. Most likely, if the safety supervisor and workers do not have a high level of safety awareness regarding construction worksites' hazards and fail to comply with safety rules, injuries and accidents will occur, even if safety management applies high-standard safety rules and procedures. Good safety behaviour amongst workers plays a significant role in increasing their perception and attention towards safety-hazard records and the importance of using safety tools and equipment. Clear and 


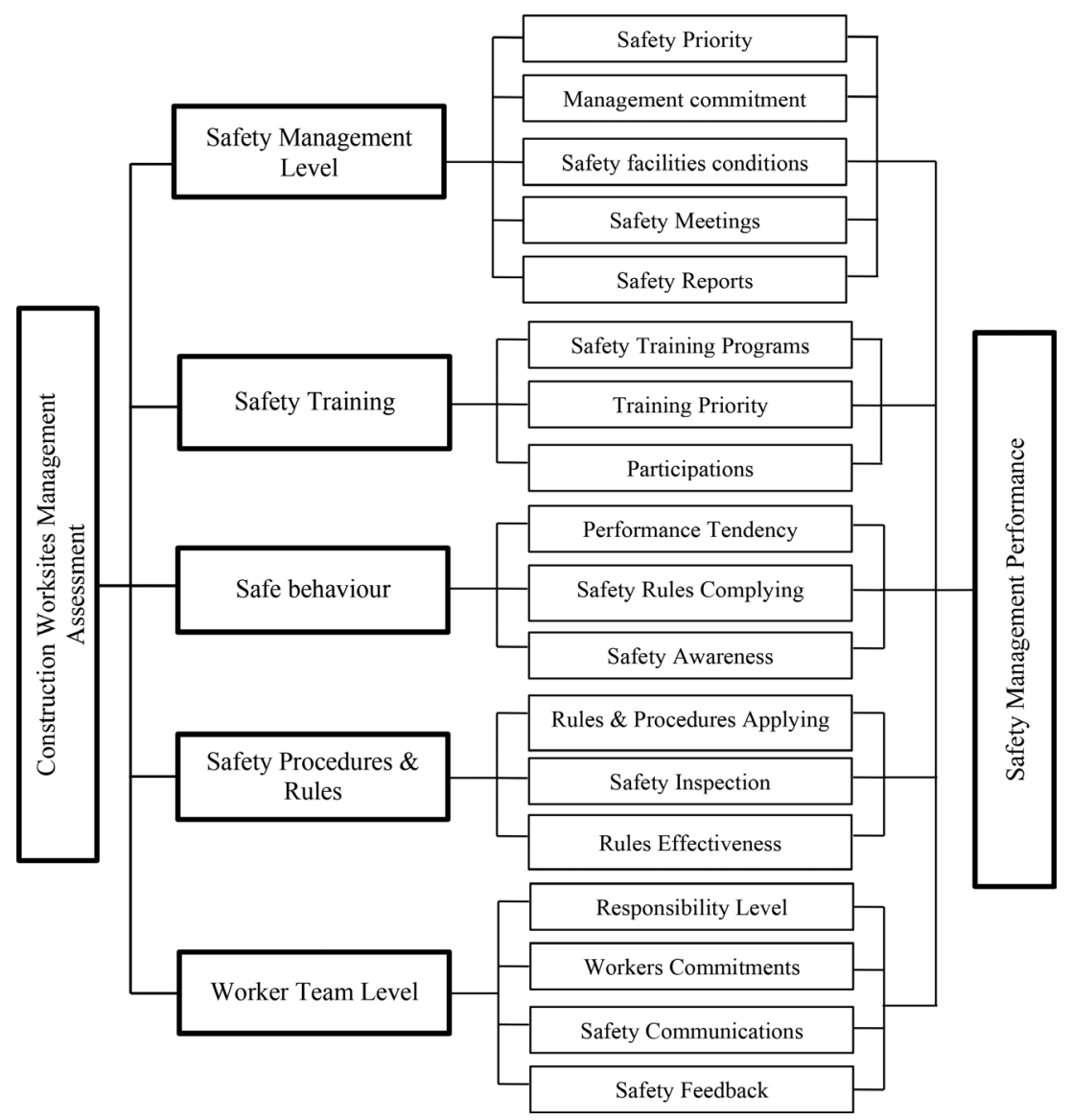

Figure 1: The main and sub-criteria list to model the uncertainties of construction worksite.

simple safety procedures and rules amongst all management levels in a company are important factors that lead to increased effectiveness of the overall SMS performance.

According to the current study's expert safety participant, some activities at construction worksites require clear and effective procedures and steps, such as using cranes and scaffolds. These types of safety rules and procedures contribute significantly to preventing accidents. Safety inspection is one of the most important procedures that prevents different types of accidents and increases workers' safety knowledge and awareness. Finally, the worker team level factor includes responsibility level, worker commitment, safety communication, and safety feedback. This factor focuses on workers and safety at construction worksites. Responsibility level refers to the level of worker concern towards safety (i.e. a worker performs his job under highly safe work conditions). In other words, the worker considers his safety and his co-workers' safety, and implements safety rules and procedures while performing his task. The level of workers' compliance with the safety rules and procedures is an important sub-factor that can impact SMS performance negatively. Figure 1 shows all criteria employed to model the uncertainties of construction worksite and evaluate the companies. Even if the top management provides middle management and safety advisors with effective safety rules, 
good safety training, and personal protective equipment, a lack of worker commitment will waste these efforts. Feedback and communication amongst workers, safety managers, safety advisors, and safety management encourage effective safety reports, which lead to appropriate identification of worksite hazards and control measures.

\subsection{Determination of safety performance elements by fuzzy sets}

This study aimed to use the fuzzy AHP approach to identify and evaluate the five most important factors affecting SMS performance, which in turn affects the safety on construction worksites, as noted above. AHP methods have been widely used to determine the importance of different factors and actions in multi-criteria problems [12, 13, 16]. Unlike previous studies, the current study evaluated the five main factors and sub-factors that can affect SMSs in construction industries. These factors and sub-factors were formulated based on previous studies focused on the safety performance at construction sites [1]. Five main factors were considered when assessing the SMSs of construction companies: site management level, safety training, safe behaviour, safety procedures and rules, and worker team level. As shown in Fig. 1, the sub-factors were then classified under each main factor, as illustrated in the proposed AHP model. The proposed model comprises four levels. The first level presents the model's main goal, which is to identify the weights of the sub-factors. The second level describes the main five factors that influence safety at construction worksites. The third level outlines the sub-factors of these main factors. Finally, the fourth level describes the effectiveness of the SMS, which is the output of the model.

The fuzzy AHP method is an aggregated technique that was developed based on Saaty's [15] fuzzy set theory and is one of the most common methods used in multi-criteria decisionmaking studies [17]. The importance of decision criteria relative to others is shown in a pair-wise comparison matrix using a numerical scale of linguistic terms based on the fuzzy AHP method. The importance of the weights and the performance ratings of the criteria are measured using this numerical scale. The current study used eight linguistic terms on a scale ranging from extremely strong (ES; $[9,9,9])$ to equally strong (EQ; $[1,1,1])$, as illustrated in Table 1. The linguistic scale in the fuzzy AHP method was used to categorize the criteria (C) based on their current status. The weights of factors were processed using multiplecriteria decision making (MCDM), which provided a fuzzy AHP model and has been used as a systematic technique to address the inaccuracy of decision makers. A qualitative evaluation of fuzzy TOPSIS techniques was conducted using these weights to determine which construction company exhibited the best safety-management performance [18].

Table 1: Fuzzy linguistic terms determined for the criterion weights comparison.

\begin{tabular}{ll}
\hline Extremely strong (ES) & $(9,9,9)$ \\
Very strong (VS) & $(7,8,9)$ \\
Strong (ST) & $(6,7,8)$ \\
Moderately strong (MS) & $(5,6,7)$ \\
Intermediate strong (IS) & $(4,5,6)$ \\
Lower intermediate strong (LIS) & $(3,4,5)$ \\
Slightly more strong (SS) & $(1,2,3)$ \\
Equally strong (EQ) & $(1,1,1)$
\end{tabular}


The following steps were used to implement the fuzzy AHP technique:

1. In the first step, the hierarchical decision-making problem is structured. This step is similar to that in the conventional AHP approach.

2. In the second step, a pair-wise fuzzy comparison matrix is developed. The pair-wise comparison judgements are represented by fuzzy triangular numbers denoted by $\tilde{\mathrm{a}}_{\mathrm{ij}}=\left(\mathrm{l}_{\mathrm{ij}}, \mathrm{m}_{\mathrm{ij}}, \mathrm{u}_{\mathrm{ij}}\right)$. As in the conventional AHP, $\mathrm{n}(\mathrm{n}-1) / 2$ judgements are required for each comparison group for a level to construct a positive fuzzy reciprocal comparison matrix $\breve{A}=\left\{\tilde{a}_{\mathrm{ij}}\right\}$. The matrix is expressed as follows.

$$
\breve{\mathrm{A}}=\left\{\tilde{\mathrm{a}}_{\mathrm{ij}}\right\}=\left(\begin{array}{ccc}
\tilde{a}_{11} & \cdots & \tilde{a}_{1 n} \\
\vdots & \ddots & \vdots \\
\tilde{a}_{n 1} & \cdots & \tilde{a}_{m n}
\end{array}\right)
$$

3. The third step consists of performing the consistency check and deriving priorities from the pair-wise comparison matrices. In the existing fuzzy AHP method, the consistency of pair-wise comparison matrices is checked. Buckley [19] stated that a fuzzy comparison matrix $\breve{\mathrm{A}}=\left\{\tilde{\mathrm{a}}_{\mathrm{ij}}\right\}$ is consistent if $\tilde{\mathrm{a}}_{\mathrm{ik}} \otimes \tilde{\mathrm{a}}_{\mathrm{kj}} \approx \tilde{\mathrm{a}}_{\mathrm{ij}}$, where $i, j, k=1,2, \ldots, n$ and $\otimes$ is the fuzzy multiplication of elements. If the pair-wise comparison matrix $(\breve{A})$ passes the consistency check, then the fuzzy priorities $W_{i}$ can be calculated with the conventional fuzzy AHP method.

4. At different levels of the decision hierarchy, the aggregate local priorities compound global priorities for the alternatives based on the weighted sum method. The final global priority of alternative i can be expressed as follows.

$$
A_{i}=\sum_{j=1}^{n} w_{j} a_{i j}
$$

where $w_{j}$ is the weight of criterion $j$ and $a_{i j}$ is the evaluation of alternative $A_{i}$ against criterion $j$. A higher value of $A_{i}$ indicates a more preferable alternative. Specific ranking procedures must be applied to defuzzify the order of alternatives. These procedures should be conducted if the priorities are fuzzy, similar to the conventional fuzzy AHP.

The improved fuzzy extent analysis of Chang's [20] method was employed to determine the weights of criteria using fuzzy triangular numbers. Hence, let $X=\{x 1, x 2, x 3, \ldots, x n\}$ be a decision set and $\mathrm{G}=\{\mathrm{g} 1, \mathrm{~g} 2, \mathrm{~g} 3, \ldots, \mathrm{gn}\}$ be the goal set for each criterion to simultaneously perform the extension analysis of each criterion. Let $M_{g i}^{j}(j=1,2, \ldots, m)$ be fuzzy triangular numbers to present the pair-wise weights of criteria. The set of fuzzy pair-wise comparison terms presented in Table 1 was developed by Saaty [15] and they were employed for decision making in this study. The inverse of the vector indicating the synthetic extent was calculated, and the Si values were obtained for each criterion as follows in eqn (2):

$$
S_{i}=\sum_{j=1}^{m} M_{g i}^{j} \otimes\left[\sum_{i=1}^{n} \sum_{j=1}^{m} M_{g i}^{j}\right]^{-1}=W=\left[w_{1}, w_{2}, \ldots, w_{n}\right]
$$


$\sum_{j=1}^{m} M_{g i}^{j}$ is obtained from fuzzy triangular numbers; the fuzzy triangular numbers used in the extent analysis can be established with a particular matrix.

The criterion weights of safety conditions were determined at the end of this process as fuzzy triangular numbers. Membership functions (MFs) can be used to express the triangular numbers as a mathematical function. Triangular MFs are specified by three parameters, where $\left(l_{i j}<m_{i j}<u_{i j}\right)$ indicates the parameters of the underlying triangular MFs. A fuzzy number is a convex fuzzy set characterized by a given interval of real numbers, each with a grade of membership degree between 0 and 1. $m_{i j}$ represents the MFs' centre. Table 2 presents the fuzzy numerical scale for the pair-wise comparison of criteria. The DM uses these weights to determine the mutual comparative importance of the safety criteria.

To build the pair-wise comparison matrix, each criterion in the set was mutually evaluated and an extension analysis was performed. The outcomes of the fuzzy synthetic extent with respect to the criteria were calculated. The pair-wise comparison was performed for each criterion in the set, the results were evaluated, and the extension analysis was performed. Therefore, eqn (2) was employed for m extent analyses of criteria; the results are presented in Table 3. Moreover, $m$ extent analyses were conducted for each criterion; the results are presented in Table 4 . The calculations of the weights for safety conditions and reliability are presented below. Other decision criteria were calculated using the same approach. Fuzzy triangular numbers were used to identify the safety-management level or safety training level of companies. The fuzzy triangular obtained for the criteria of the SMS of a construction company is presented in Table 3.

The results of the fuzzy synthetic extents (SC1) for each criterion are presented in Table 4. The information used for the assessment was provided by the decision makers (i.e. four

Table 2: Fuzzy pair-wise comparison of construction project criteria.

Fuzzy pair-wise

\begin{tabular}{lccccc} 
decision matrix & C1 & C2 & C3 & C4 & C5 \\
\hline C1: Safety- & $(1,1,1)$ & $(5,6,7)$ & $(1 / 8,1 / 7,1 / 6)$ & $(6,7,8)$ & $(2,2.5,5)$ \\
Management Level & & & & & \\
C2: Safety Training & $(1 / 7,1 / 6,1 / 5)$ & $(1,1,1)$ & $(1 / 7,1 / 6,1 / 5)$ & $(1 / 8,1 / 7,1 / 6)$ & $(1 / 6,1 / 5,1 / 4)$ \\
C3: Safe behaviour & $(6,7,8)$ & $(5,6,7)$ & $(1,1,1)$ & $(1 / 6,1 / 5,1 / 4)$ & $(5,6,7)$ \\
C4: Safety & $(1 / 8,1 / 7,1 / 6)$ & $(6,7,8)$ & $(4,5,6)$ & $(1,1,1)$ & $(1 / 6,1 / 5,1 / 4)$ \\
Procedures \& Rules & & & & & \\
C5: Work Team Level & $(1 / 5,1 / 2.5,1 / 2)$ & $(4,5,6)$ & $(1 / 7,1 / 6,1 / 5)$ & $(4,5,6)$ & $(1,1,1)$ \\
\hline
\end{tabular}

Table 3: Fuzzy triangular numbers used to define the weights of decision criteria.

\begin{tabular}{ll}
\hline Fuzzy pair-wise decision matrix & Weights \\
\hline C1: Safety-Management Level & $(14.12,16.64,21.17)$ \\
C2: Safety Training & $(1.58,1.68,1.85)$ \\
C3: Safe Behaviour & $(17.17,20.20,23.25)$ \\
C4: Safety Procedures \& Rules & $(10.46,12.34,14.42)$ \\
C5: Work Team Level & $(9.34,11.57,13.70)$ \\
\hline
\end{tabular}


Table 4: Fuzzy weights of the decision criteria.

\begin{tabular}{lc} 
Fuzzy pair-wise decision matrix & Weights \\
\hline C1: Safety-Management Level & $(0.22,0.27,0.34)$ \\
C2: Safety Training & $(0.02,0.03,0.04)$ \\
C3: Safe Behaviour & $(0.26,0.32,0.37)$ \\
C4: Safety Procedures \& Rules & $(0.16,0.20,0.23)$ \\
C5: Work Team Level & $(0.21,0.23,0.40)$
\end{tabular}

expert decision makers in safety) and the aggregated fuzzy numbers were obtained by fuzzy synthetic extent analysis. The calculations are presented below.

$$
\begin{aligned}
& {\left[\sum_{i=1}^{n} \sum_{j=1}^{m} M_{i}^{j}\right]^{-1}=[64.85,62.42,62.05]^{-1}=[1 / 64.85,1 / 62.42,1 / 62.05] } \\
S_{C_{1}} & =\sum_{j=1}^{m} M_{i}^{j} \otimes\left[\sum_{i=1}^{n} \sum_{j=1}^{m} M_{i}^{j}\right]^{-1} \\
& =(14.12,16.64,21.17) \otimes(1 / 64.85,1 / 62,42,1 / 62.05)=(0.22,0.27,0.34)
\end{aligned}
$$

\section{FUZZY TOPSIS METHODOLOGY FOR ASSESSING SAFETY CONDITIONS IN THE CONSTRUCTION INDUSTRY}

After the fuzzy criterion weights were determined by the fuzzy AHP method, the safety conditions of each construction company were assessed based on the selected criteria. Table 5 shows the fuzzy linguistic variables and their term sets for the construction companies' health and safety-management parameters.

In this study, the safety conditions of construction companies were assessed using a hybrid fuzzy decision-making approach. Antonsen [21] stated that a weak link exists between the safety assessment and 'actual' safety conditions in an organization. He also stated that failures of foresight are inevitable if safety culture assessments are based on questionnaires alone. Self-assessment questionnaires are subject to inaccurate or incomplete information; previous studies have found that many companies or managers are concerned that the data of safety and health conditions might be used against them [22]. The judgements of decision makers are crucial. To order or harmonize their judgements, videos or some other means can be used in the office meetings to reach the common assessment scores.

In a classical assessment approach, the assessment is performed in accordance with national compliance requirements using a 5-point Likert scale. In this scale comparison, 1 refers to no effort being made regarding the sub-criterion under consideration, 2 refers to a small amount of effort being made but compliance still not being met, 3 refers to a small amount of effort required to achieve the minimum requirements of compliance, 4 refers to endeavours that are in compliance to standards, and 5 refers to standards that are higher than the national standards. However, this assessment approach has limitations, as an expert's judgement is often qualitative and based on linguistic assessments. Linguistic terms are used by experts and other individuals to define parameters. Table 6 illustrates the fuzzy linguistic terms employed to determine the importance of attributes and the rating of alternative companies according to the parameters. 
Table 5: Fuzzy linguistic variables and their term sets for the construction industry.

1. Safety-Management

Level

Fuzzy Linguistic Terms

\begin{tabular}{|c|c|c|c|c|c|}
\hline Safety Priority & Very low & Low & Moderate & High & Very high \\
\hline $\begin{array}{l}\text { Management's } \\
\text { Commitment }\end{array}$ & Very low & Low & Moderate & High & Very high \\
\hline $\begin{array}{l}\text { Safety Facilities } \\
\text { Conditions }\end{array}$ & Poor & Fair & Good & Very good & Excellent \\
\hline Safety Meetings & Very rare & Rare & Sometimes & Often & Always \\
\hline Safety Reports & $\begin{array}{l}\text { Low } \\
\text { importance }\end{array}$ & $\begin{array}{l}\text { Slightly } \\
\text { important }\end{array}$ & $\begin{array}{l}\text { Moderately } \\
\text { important }\end{array}$ & $\begin{array}{l}\text { Highly } \\
\text { important }\end{array}$ & $\begin{array}{l}\text { Extremely } \\
\text { important }\end{array}$ \\
\hline 2. Safety Training & \multicolumn{5}{|c|}{ Fuzzy Linguistic Terms } \\
\hline $\begin{array}{l}\text { Safety Training } \\
\text { Programmes }\end{array}$ & Poor & Fair & Good & Very good & Excellent \\
\hline Training Priority & Very low & Low & Moderate & High & Very high \\
\hline Participation & Low & Slightly low & Moderate & Slightly high & High \\
\hline 3. Safe Behaviour & \multicolumn{5}{|c|}{ Fuzzy Linguistic Terms } \\
\hline $\begin{array}{l}\text { Performance } \\
\text { Tendency }\end{array}$ & Risky & $\begin{array}{l}\text { Slightly } \\
\text { Risky }\end{array}$ & Normal & Slightly Safe & Safe \\
\hline $\begin{array}{l}\text { Safety Rules } \\
\text { Compliance }\end{array}$ & $\begin{array}{l}\text { Extremely } \\
\text { unacceptable }\end{array}$ & unacceptable & Normal & $\begin{array}{l}\text { Slightly } \\
\text { acceptable }\end{array}$ & Acceptable \\
\hline Safety Awareness & Unaware & $\begin{array}{l}\text { Slightly } \\
\text { aware }\end{array}$ & $\begin{array}{l}\text { Somewhat } \\
\text { average }\end{array}$ & $\begin{array}{l}\text { Moderately } \\
\text { aware }\end{array}$ & $\begin{array}{l}\text { Extremely } \\
\text { aware }\end{array}$ \\
\hline
\end{tabular}

4. Safety Procedures \& Rules

Fuzzy Linguistic Terms

\begin{tabular}{|c|c|c|c|c|c|}
\hline $\begin{array}{l}\text { Application } \\
\text { of Rules \& } \\
\text { Procedures }\end{array}$ & Never & Rarely & Sometimes & Often & Always \\
\hline $\begin{array}{l}\text { Safety Inspection } \\
\text { Frequency }\end{array}$ & Never & Rarely & Sometimes & Often & Always \\
\hline $\begin{array}{l}\text { Effectiveness of } \\
\text { Procedures \& } \\
\text { Rules }\end{array}$ & Low & Slightly low & Moderate & Slightly high & High \\
\hline
\end{tabular}

5. Worker Team Level

Fuzzy Linguistic Terms

\begin{tabular}{llllll}
\hline $\begin{array}{l}\text { Responsibility } \\
\text { Level }\end{array}$ & Very low & Low & Moderate & High & Very high \\
$\begin{array}{l}\text { Workers' } \\
\text { Commitment }\end{array}$ & Very low & Low & Moderate & High & Very high \\
$\begin{array}{l}\text { Safety } \\
\text { Communications }\end{array}$ & Poor & Fair & Good & Very good & Excellent \\
Safety Feedback & Poor & Fair & Good & Very good & Excellent \\
\hline
\end{tabular}


Table 6: Linguistic terms and their numerical intervals for fuzzy TOPSIS.

Fuzzy Linguistic Terms for Decision Making

Numerical Values

Very Low Important (VLI)

$(1,2,3)$

Low Important (LI)

$(2,3,4)$

Moderately Important (MI)

$(3,4,5)$

Highly Important (HI)

$(4,5,6)$

Extremely Important (EI)

$(5,7,9)$

Although four companies were assessed, this study only presents the complete details of the calculations for the assessment of safety and health conditions at only one construction company. Taylan et al. [13] stated that TOPSIS is an attractive method and requires limited subjective inputs from decision makers, where the criteria are not equally important and the input criterion-related information is not precisely known. An integrated fuzzy AHP and fuzzy TOPSIS method can improve the quality of decisions made regarding the ranking of alternative scenarios. In this study, an integrated fuzzy FAHP and fuzzy TOPSIS approach was employed for compressor selection using different scenarios. Zhang and Wei [23] used an extension of VIKOR and TOPSIS methods for decision-making problems based on a hesitant fuzzy set to represent the 'closeness to the ideal,' which originated in the compromise programming method. Torfi et al. [24] used the fuzzy MCDM approach for the weights of the objects phrase in the location routing problem to determine the relative weights of criteria using trapezium fuzzy numbers in decision-making problems.

\subsection{Results and findings of the applied methodologies}

The decision-making model presented in this study is described by fuzzy membership functions $\mu_{\mathrm{g}}(\mathrm{x})$, where $\mathrm{x}$ is an element of the crisp set. The following fuzzy linguistic terms were used to assess the safety and health conditions at workplaces: very low importance (VLI), low importance (LI), moderately important (MI), highly important (HI), and extremely important (EI). The steps for implementing the fuzzy TOPSIS methodology and its results are described below.

Step 1: The importance of all main criteria and sub-criteria was considered to assess the safety conditions at workplaces in a holistic manner. Therefore, the fuzzy linguistic terms determined in Table 5 were used to calculate the outcomes. Equation (3) was used to average the fuzzy numerical values assigned for each main criterion and sub-criteria. Hence, let $N=\left\{n_{1}, n_{2}, \ldots, n_{6}\right\}$ be the set of construction companies to be assessed. First, fuzzy numerical values were used to evaluate each company with regard to the criteria, and then, a rating order was determined for the companies by multiplying the matrix of outcomes with the vector of criterion weights to determine the safety conditions at workplaces.

$$
\tilde{X}_{i j}=\frac{1}{N}\left\{\tilde{z}_{i j}^{(1)}+\tilde{z}_{i j}^{(2)}+\ldots+\tilde{z}_{i j}^{(N)}\right\}
$$

where $\hat{z}_{i j}$ are fuzzy numerical values assigned by the $k^{\text {th }}$ decision maker from the assessed company with respect to a criterion and (+) indicates the fuzzy arithmetic summation function. $X=\left(\hat{z}_{i j}\right)_{\mathrm{nxm}}$ is a fuzzy decision matrix characterized by fuzzy numerical values. A fuzzy 
term set was used to determine the rate of companies for safety conditions to evaluate the reliability of a workplace. The term set $T\left(\hat{\mathrm{z}}_{i j}\right)$ is the set of linguistic terms within $\{1, \ldots, 9\}$. Similarly, $\mu\left(\hat{z}_{i j}\right)$ is an MF used to associate each value of the criteria with its fuzzy equivalences. For example, the 'management commitment' of the company covers the sub-criteria 'safety priority, responsibilities of supervisors, and adequacy of safety tools and equipment' and can be presented by the linguistic term set as $T\left(\hat{\mathrm{z}}_{i j}\right)=\{$ very low, low, moderate, high, and very high\}.

Step 2: It is possible to avoid complex calculations; a linear normalization is used to convert the various measurement scales into comparable scales. Hatami-Marbini and Tavana [25] stated that the decision matrices are homogenous and that the range of each component of the normalized triangular fuzzy numbers lies within $[0,1] . \tilde{R}_{i j}$ is the normalized fuzzy decision matrix. Equation (4) presents this fuzzy decision matrix for safety conditions at workplaces with regard to the criteria. $\mathrm{B}$ and $\mathrm{C}$ are the set of benefit criteria and cost criteria [26], respectively. Equation (5) shows the maximum and minimum values of the fuzzy numerical values $\left(\hat{\mathrm{z}}_{i j}\right)$.

$$
\tilde{R}_{i j}=\left[\tilde{r}_{i j}\right]_{m \times n}, i=1,2, \ldots, m ; j=1,2, \ldots, n .
$$

where

$$
\begin{aligned}
\tilde{r}_{i j}=\left(r_{i j}^{l}, r_{i j}^{m}, r_{i j}^{u}\right) & =\left(\frac{z_{i j}^{l}}{c_{j}^{*}}, \frac{z_{i j}^{m}}{c_{j}^{*}}, \frac{z_{i j}^{u}}{c_{j}^{*}}\right), \quad i=1,2,3, \ldots, m, j \in B . \\
c_{j}^{*} & =\max _{t}\left[z_{i j}^{u}\right], j=1,2,3, \ldots ., n . \\
c_{j}^{-} & =\min _{t}\left[z_{i j}^{l}\right], j=1,2,3, \ldots ., n .
\end{aligned}
$$

The weighted normalized fuzzy decision matrix $(\tilde{V})$ can be defined as follows. Equation (6) illustrates the weighted normalized fuzzy decision matrix. This matrix is used to transform the crisp outcomes of safety conditions at workplaces to evaluate the reliability of a workplace by the triangular fuzzy numbers within the interval $[0,1]$.

$$
\tilde{V}=\left[\tilde{v}_{i j}\right]_{\mathrm{mxn}}, i=1,2, \ldots, m ; j=1,2, \ldots, n
$$

where

$$
\tilde{v}_{i j}=\left(v_{i j}^{l}, v_{i j}^{m}, v_{i j}^{u}\right)=w_{j} \otimes \tilde{r}_{i j}=\left(w_{j}^{l} r_{i j}^{l}, w_{j}^{m} r_{i j}^{m}, w_{j}^{u} r_{i j}^{u}\right)
$$

The fuzzy positive ideal solution (FPIS) and fuzzy negative ideal solution (FNIS) are denoted by $\mathrm{A}^{*}$ and $\mathrm{A}-$, respectively, which can be presented as follows: $\mathrm{A}^{*}=\left(v_{1}^{*}, v_{2}^{*}, \ldots, v_{n}^{*}\right)$, $A^{-}=\left(v_{1}^{-}, v_{2}^{-}, \ldots, v_{n}^{-}\right)$.

This study discusses the detailed calculations for the Company 1 criterion 'safety management level'. Table 7 shows the fuzzy linguistic terms allocated for this criterion. Four key qualified staff (DMs) participated in the decision making regarding the parameters using the linguistic terms presented in Table 7. Equation (3) was used to calculate the average decision for each main criterion and sub-criteria. The fuzzy triangular numbers assigned by DMs to each sub-criteria for the safety-management level were determined and aggregated. The results are presented in Table 8.

For example, DM 2 concluded that the 'safety priority' for company 1 is 'HI-highly important' linguistically, with a numerical value of $(4,5,6)$. However, the other DMs had different opinions, finding that the 'safety priority' of this company was (LI), (LI) and (HI) 
Table 7: Decision matrix for safety-management level by fuzzy linguistic terms.

\begin{tabular}{lcccc}
\hline C1: Safety-Management Level & DM1 & DM2 & DM3 & DM4 \\
\hline C11:Safety Priority & LI & HI & LI & HI \\
& $(2,3,4)$ & $(4,5,6)$ & $(2,3,4)$ & $(4,5,6)$ \\
C12:Management Commitment & EI & HI & LI & MI \\
& $(5,7,9)$ & $(4,5,6)$ & $(2,3,4)$ & $(3,4,5)$ \\
C13:Safety Facilities Conditions & MI & HI & HI & EI \\
& $(3,4,5)$ & $(4,5,6)$ & $(4,5,6)$ & $(5,7,9)$ \\
C14:Safety Meetings & MI & HI & LI & LI \\
& $(3,4,5)$ & $(4,5,6)$ & $(2,3,4)$ & $(2,3,4)$ \\
C15:Safety Reports & HI & EI & MI & MI \\
& $(4,5,6)$ & $(5,7,9)$ & $(3,4,5)$ & $(3,4,5)$ \\
\hline
\end{tabular}

Table 8: Final aggregation of company grades with respect to all criteria using fuzzy triangular numbers.

\begin{tabular}{lccccc}
\hline Companies $\tilde{V}_{i j}$ & $\mathrm{C}_{1}$ & $\mathrm{C}_{2}$ & $\mathrm{C}_{3}$ & $\mathrm{C}_{4}$ & $\mathrm{C}_{5}$ \\
\hline Construction & $(0.11,0.19$, & $(0.01,0.01$, & $(0.12,0.24$, & $(0.09,0.16$, & $(0.12,0.17$, \\
Company 1 & $0.29)$ & $0.03)$ & $0.31)$ & $0.23)$ & $0.36)$ \\
Construction & $(0.11,0.18$, & $(0.01,0.02$, & $(0.10,0.16$, & $(0.10,0.14$, & $(0.12,0.17$, \\
Company 2 & $0.29)$ & $0.03)$ & $0.24)$ & $0.23)$ & $0.36)$ \\
Construction & $(0.11,0.18$, & $(0.02,0.02$, & $(0.12,0.20$, & $(0.10,0.14$, & $(0.11,0.15$, \\
Company 3 & $0.28)$ & $0.04)$ & $0.26)$ & $0.20)$ & $0.30)$ \\
Construction & $(0.10,0.17$, & $(0.01,0.02$, & $(0.14,0.23$, & $(0.09,0.16,23)$ & $(0.09,0.16$, \\
Company 4 & $0.28)$ & $0.03)$ & $0.33)$ & & $0.33)$ \\
\hline
\end{tabular}

linguistically; the numerical equivalences of each of these linguistic terms are presented in Table 7. Hence, the averages of each sub-criteria and criterion were calculated because all criteria are important for decision making. The assessment of all companies with regard to the criteria is presented in Table 9. The sample calculations for the rating of decisions made by decision makers (experts) for 'safety priority' was calculated and is presented below. As all weights of the decision criteria were determined, a maximum-minimum compositional rule of inference could be employed to transform the crisp decisions into fuzzy equivalences. In Step 2 of the fuzzy TOPSIS application, the fuzzy decision matrix was normalized to determine the performance of compressors in terms of fuzzy numerical values with regard to the main criteria. Equation (5) was used to determine the maximum value of each $c_{j}^{*}$ for the construction companies. For example, $c_{1}{ }^{*}$ is equal to 6.0 for Construction Company 1 , and the other ' $c_{j}^{*}$, values are presented in Table 9. The details of the calculations are given below.

$$
\begin{gathered}
\left(R_{11}\right)=\frac{(2,3,4)+(5,7,9)+(3,4,5)+(3,4,5)+(4,5,6)}{5}=(3.4,4.6,5.7) \\
c_{11}^{*}=\max _{1}[(3.4,4.6,5.7), \ldots,(3.9,5.2,6.6),(3.4,4.8,6.0)=6.6
\end{gathered}
$$


Table 9: Decision matrix for construction companies with regard to the criteria.

\begin{tabular}{lcccccc}
\hline Rij & $\mathrm{C} 1$ & $\mathrm{C} 2$ & $\mathrm{C} 3$ & $\mathrm{C} 4$ & $\mathrm{C} 5$ & $\mathrm{cj} *$ \\
\hline $\begin{array}{l}\text { Construction } \\
\text { Company 1 }\end{array}$ & $(3.4,4.6,5.7)$ & $(3.2,4.3,5.4)$ & $(3.6,4.9,5.9)$ & $(3.9,5.2,6.6)$ & $(3.4,4.8,6.0)$ & 6.6 \\
Construction & $(3.6,5.0,6.3)$ & $(3.6,4.8,6.0)$ & $(2.8,3.7,4.7)$ & $(4.5,5.2,7.3)$ & $(4.0,5.3,6.5)$ & 7.3 \\
Company 2 & & & & & & \\
Construction & $(3.5,4.8,6.0)$ & $(4.3,5.2,6.4)$ & $(3.3,4.5,5.8)$ & $(4.3,5.5,7.2)$ & $(3.8,4.6,5.4)$ & 7.2 \\
Company 3 & & & & & & \\
Construction & $(3.2,4.4,5.8)$ & $(3.5,4.7,5.2)$ & $(3.8,5.1,6.3)$ & $(4.0,5.5,7.0)$ & $(3.1,4.9,5.8)$ & 7.0 \\
Company 4 & & & & & & \\
Weights & $(0.22,0.27$, & $(0.02,0.03$, & $(0.26,0.32$, & $(0.16,0.20$, & $(0.21,0.23$, & \\
& $0.34)$ & $0.04)$ & $0.37)$ & $0.23)$ & $0.40)$ & \\
\hline
\end{tabular}

Fuzzification refers to the representation of the performance of construction companies in terms of fuzzy terms and implications. As shown in Table 9, the decisions presented are in crisp numerical values and must be transformed into fuzzy equivalences within the interval $[0,1]$. As a result of these calculations, a set of fuzzified values $\left(\tilde{r}_{i j}\right)$ will be obtained for each criterion. Equation (4) was used for these calculations. The fuzzified values $\left(\tilde{r}_{i j}\right)$ were presented as the matrix $\tilde{R}_{i j}$ and are given in Equation (7); these values are fuzzified membership degrees presenting the performance rates of the construction companies.

$$
\begin{gathered}
\tilde{r}_{25}=\left(\frac{4.0}{7.3}, \frac{5.3}{7.3}, \frac{6.5}{7.3}\right)=(0.55,0.73,0.89) \\
\tilde{R}_{i j}=\left[\begin{array}{cccc}
r_{11} & r_{12} & \ldots & r_{1 j} \\
r_{21} & r_{22} & \ldots & r_{2 j} \\
\ldots & \ldots & \ldots & \ldots \\
r_{i 1} & r_{i 2} & \ldots & r_{i j}
\end{array}\right]
\end{gathered}
$$

The fuzzified values presented in Table 9 were weighted, and the outcomes indicate the performance of each construction company. This is the step at which the fuzzy AHP approach is integrated with the fuzzy TOPSIS methodology. Equation (6) was used to determine the weighted fuzzified values. For example, $\mathrm{V}_{25}=(0.12,0.17,0.36)$ is a fuzzy triangular rate indicating the 'safety training level' of Construction Company 2. The detailed calculation is presented below:

$$
\tilde{V}_{25}=\tilde{r}_{25} \otimes \tilde{w}_{5}=(0.55,0.73,0.89) \otimes(0.21,0.23,0.40)=(0.12,0.17,0.36)
$$

Table 8 presents the performance rating of all construction companies with regard to the main criteria. The table shows the performance grades determined by decision makers, which are triangular fuzzy numbers. These numbers are not particularly meaningful for performing an analysis of the companies to enable the final decision. Therefore, the weighted fuzzy decisions must be normalized. Normalization is a defuzzification process of the decision matrix 
to determine the distance of these performance values to the ideal performance value. The distances can be used to find the similarity co-efficient and ranking order of the construction companies. The distances can be on both sides; hence, one side can be defined as the FPIS, and the other side can be defined as the FNIS.

$d\left(d_{i}^{*}, d_{i}^{-}\right)$is the distance measurement between two fuzzy numerical values. The closeness coefficient is used to determine the performance rate of the companies. The values of $d_{i}^{*}$ and $d_{i}^{-}$of each alternative company are calculated, and the decision is made by ordering the performance of the companies.

$$
\begin{aligned}
d_{1}^{+} & =\sqrt{\left(\sum_{j=1}^{n} \frac{(1-0.11)^{2}+(1-0.19)^{2}+(1-0.29)^{2}}{3}+\cdots+\frac{(1-0.12)^{2}+(1-0.17)^{2}+(1-0.36)^{2}}{3}\right)} \\
& =3.56 \\
d_{1}^{-} & =\sqrt{\left(\sum_{j=1}^{n} \frac{(0-0.11)^{2}+(0-0.19)^{2}+(0-0.29)^{2}}{3}+\cdots+\frac{(0-0.12)^{2}+(0-0.17)^{2}+(0-0.36)^{2}}{3}\right)} \\
& =0.187
\end{aligned}
$$

Table 10 presents the closeness coefficients $\left(C C_{i}\right)$ of all companies to the ideal distance. The closeness coefficient of each alternative company was calculated by eqn (8). The FPIS and FNIS of the scenarios were used to determine the total distances from the ideal value. The result becomes notably closer to the FPIS and further from the FNIS as $C C_{i}$ approaches 1 . Therefore, according to the closeness coefficient, the ranking order of all companies was determined and the best alternative was selected among four alternative companies. The ranking order of the companies based on the closeness coefficient is given in Table 8 .

$$
C C_{i}=\frac{d_{i}^{-}}{d_{i}^{*}+d_{i}^{-}}=\frac{0.187}{3.56+0.187}=0.05
$$

The closeness coefficient measures the performance efficiency of construction companies. Hence, the results show that the similarity coefficient of Construction Company 1 is 0.05 , i.e. this company has applications closer to the ideal values, followed by Company 4 (0.047). The ranking order of the companies based on closeness coefficients is presented in Table 10 .

The similarity coefficients of Companies 2 and 3 are 0.042 and 0.039 , respectively, i.e. these construction companies are far from the ideal value. According to the results in Table 10,

Table 10: Efficiency rates and closeness coefficients of the companies.

\begin{tabular}{lcccc}
\hline Construction Companies & FPIS $\left(d_{i}^{*}\right)$ & FNIS $\left(d_{i}^{-}\right)$ & $\begin{array}{c}\text { Similarity } \\
\text { co-efficient } \\
\left(\mathrm{CC}_{\mathrm{i}}\right)\end{array}$ & $\begin{array}{c}\text { Ranking of the } \\
\text { Construction } \\
\text { Companies }\end{array}$ \\
\hline Construction Company 1 & 3.56 & 0.187 & 0.050 & 1 \\
Construction Company 2 & 3.65 & 0.159 & 0.042 & 3 \\
Construction Company 3 & 3.66 & 0.148 & 0.039 & 4 \\
Construction Company 4 & 3.60 & 0.176 & 0.047 & 2 \\
\hline
\end{tabular}


the ranking of construction companies with regard to SMS performance is as follows: Company $1>$ Company $4>$ and Company $2>$ Company 3 .

According to the results of the current study, Company 1 had the best performance out of the four companies considered. These results reflect the impact of the comprehensive safety-management practices strategy implemented by Company 1; this company distinguished itself from the other companies by applying different safety-management practices, such as offering high-quality safety training for existing and new workers and providing an intensive safety awareness programme throughout the year via posters, workshops, and digital display screens. In addition, the safety-management team at Company 1 conducted regular meetings concerning the safety issues of its construction sites, such as the effectiveness of safety inspections, accident percentages and types, and compliance with rules and procedures. The senior safety managers regularly attended the meetings to make decisions related to safety-management practices. Finally, Company 1 applied different specific training sessions, such as sessions regarding construction hazards (e.g. crane hazards and scaffold hazards), and encouraged workers to attend these training sessions. These good management practices led Company 1 to have the highest ranking.

\section{CONCLUSIONS}

Numerous factors (i.e. safety-management level, safety training, safe behaviour, safety rules, and level of teamwork) affect the performance effectiveness of SMSs, particularly at construction companies. Neglecting these factors leads to system failure and serious accidents, resulting in a company's loss of people, materials, and equipment. Recognizing these factors is critical to the ability of a construction company to increase its level of SMS productivity. A construction company can increase the productivity of its system by identifying which factors contribute significantly to system performance. The current study developed a model that can be used to identify the most important factors impacting a construction SMS. The importance of these factors and their sub-factors was determined using the fuzzy AHP technique, and the effectiveness of the four construction companies' SMSs was determined via fuzzy TOPSIS. The results of the current study confirm that the fuzzy AHP technique is a useful method for evaluating MCDM regarding safety management and simple methods that construction companies can apply.

Performance assessment of companies is a highly complex multidisciplinary task, the decision criteria are non-linear, and several quantitative and qualitative attributes have to be taken into consideration. It is very hard to find all criteria and sub-criteria together for decision making in the assessment performance assessment. The criteria and sub-criteria set is able to be used for the development of a decision support system and even for the expert system to assess the safety performance of companies. Moreover, four decision makers are involved in the decision-making process. Hence, the criteria determination, and hybridization of Fuzzy AHP and fuzzy TOPSIS is the base of the fuzzy model developed.

\section{REFERENCES}

[1] Vinodkumar, M.N. \& Bhasi, M., A study on the impact of management system certification on safety management. Safety Science, 49(3), pp. 498-507, 2011. http://dx.doi.org/10.1016/j.ssci.2010.11.009

[2] Sawacha, E., Naoum, S. \& Fong, D., Factors affecting safety performance on construction sites. International Journal of Project Management, 17(5), pp. 309-315, 1999. http://dx.doi.org/10.1016/S0263-7863(98)00042-8 
[3] van der Molen, H., Koningsveld, E., Haslam, R. \& Gibb, A., Ergonomics in building and construction: time for implementation. Applied Ergonomics, 36(4), pp. 387-389, 2005.

http://dx.doi.org/10.1016/j.apergo.2005.01.003

[4] Al-Refaie, A., Factors affect companies' safety performance in Jordan using structural equation modeling. Safety Science, 57, pp. 169-178, 2013.

http://dx.doi.org/10.1016/j.ssci.2013.02.010

[5] Ai Lin Teo, E. \& Yean Yng Ling, F., Developing a model to measure the effectiveness of safety management systems of construction sites. Building and Environment, 41(11), pp. 1584-1592, 2006.

http://dx.doi.org/10.1016/j.buildenv.2005.06.005

[6] Goetsch, D.L., Occupational Safety and Health, 4th edn., Upper Saddle River, NJ: Prentice Hall, 2002.

[7] Jannadi, O.A. \& Bu-Khamsin, M.S., Safety factors considered by industrial contractors in Saudi Arabia. Building and Environment, 37(5), pp. 539-547, 2002. http://dx.doi.org/10.1016/S0360-1323(01)00056-7.

[8] Tam, C.M., Tong, T.K.L., Chiu, G.C.W. \& Fung, I.W.H., Non-structural fuzzy decision support system for evaluation of construction safety management system. International Journal of Project Management, 20(4), pp. 303-313, 2002.

http://dx.doi.org/10.1016/S0263-7863(00)00055-7.

[9] Ismail, Z., Doostdar, S. \& Harun, Z., Factors influencing the implementation of a safety management system for construction sites. Safety Science, 50(3), pp. 418-423, 2012. http://dx.doi.org/10.1016/j.ssci.2011.10.001.

[10] Zhou, Z., Goh, Y.M. \& Li, Q., Overview and analysis of safety management studies in the construction industry. Safety Science, 72, pp. 337-350, 2015. http://dx.doi.org/10.1016/j.ssci.2014.10.006.

[11] Zou, P.X.W. \& Sunindijo, R.Y., Skills for managing safety risk, implementing safety task, and developing positive safety climate in construction project. Automation in Construction, 34, pp. 92-100, 2013.

http://dx.doi.org/10.1016/j.autcon.2012.10.018

[12] Dağdeviren, M. \&Yüksel, İ., Developing a fuzzy analytic hierarchy process (AHP) model for behavior-based safety management. Information Science, 178(6), pp. 1717-1733, 2008.

http://dx.doi.org/10.1016/j.ins.2007.10.016.

[13] Taylan, O., Bafail, A.O., Abdulaal, R.M.S. \& Kabli, M.R., Construction projects selection and risk assessment by fuzzy AHP and fuzzy TOPSIS methodologies. Applied Soft Computing, 17, pp. 105-116, 2014.

http://dx.doi.org/10.1016/j.asoc.2014.01.003.

[14] Aguarón, J., Escobar, M.T. \& Moreno-Jiménez, J.M., Consistency stability intervals for a judgement in AHP decision support systems. European Journal of Operational Research, 145(2), pp. 382-393, 2003. http://dx.doi.org/10.1016/S0377-2217(02)00544-1

[15] Saaty, T.L., Decision Making with Dependence and Feedback: The Analytic Network Process, Pittsburgh: RWS Publications, 2001.

[16] Saaty, T.L., Multi-Criteria Decision Making: The Analytic Hierarchy Process, Pittsburgh: RWS Publications, 1988. 
[17] Kaya, T. \& Kahraman, C., Multicriteria renewable energy planning using an integrated fuzzy VIKOR \& AHP methodology: the case of Istanbul. Energy, 35(6), pp. 2517-2527, 2010. http://dx.doi.org/10.1016/j.energy.2010.02.051.

[18] Lee, G., Jun, K.-S. \& Chung, E.-S., Integrated multi-criteria flood vulnerability approach using fuzzy TOPSIS and Delphi technique. Natural Hazards and Earth System Science, 13(5), pp. 1293-1312, 2013. http://dx.doi.org/10.5194/nhess-13-1293-2013.

[19] Buckley, J.J., Fuzzy hierarchical analysis. Fuzzy Sets and Systems, 17(3), pp. 233-247, 1985.

http://dx.doi.org/1 0.1016/0165-0114(85)90090-9.

[20] Chang, D., Applications of the extent analysis method on fuzzy AHP. European Journal of Operational Research, 95(3), pp. 649-655, 1996. http://dx.doi.org/10.1016/0377-2217(95)00300-2.

[21] Antonsen, S., Safety Culture: Theory, Method and Improvement, Farnham, UK: Ashgate Press, 2009.

[22] Noweir, M.H., Alidrisi, M.M., Al-Darrab, I.A. \& Zytoon, M.A., Occupational safety and health performance of the manufacturing sector in Jeddah Industrial estate, Saudi Arabia: A 20-years follow-up study. Safety Science, 53, pp. 11-24, 2013. http://dx.doi.org/10.1016/j.ssci.2012.09.005.

[23] Zhang, N. \& Wei, G., Extension of VIKOR method for decision making problem based on hesitant fuzzy set. Applied Mathematical Modelling, 37(7), pp. 4938-4947, 2013. http://dx.doi.org/10.1016/j.apm.2012.10.002.

[24] Torfi, F., Farahani, R.Z. \& Mahdavi, I., Fuzzy MCDM for weight of object's phrase in location routing problem. Applied Mathematical Modelling, 40(1), pp. 526-541, 2016. http://dx.doi.org/10.1016/j.apm.2015.06.001.

[25] Hatami-Marbini, A. \& Tavana, M., An extension of the Electre I method for group decision-making under a fuzzy environment. Omega, 39(4), pp. 373-386, 2011. http://dx.doi.org/10.1016/j.omega.2010.09.001.

[26] Taylan,O., Kaya, D. \& Demirbas, A., An integrated multi attribute decision model for compressor selection in petrochemical industry applying fuzzy set theory. Energy conversion \& Management, Energy, 117, pp. 501-512, 2016. 